\title{
Web-Based Multidomain Lifestyle Programs for Brain Health: Comprehensive Overview and Meta-Analysis
}

Linda MP Wesselman ${ }^{1}$, MSc; Astrid M Hooghiemstra ${ }^{1,2}$, PhD; Linda J Schoonmade ${ }^{3}$, MSc; Marjolein CJ de Wit ${ }^{1}$, MSc; Wiesje M van der Flier ${ }^{1,4}$, PhD; Sietske AM Sikkes ${ }^{1,4,5}, \mathrm{PhD}$

\footnotetext{
${ }^{1}$ Alzheimer Center Amsterdam, Department of Neurology, Amsterdam Neuroscience, Vrije Universiteit Amsterdam, Amsterdam UMC, Amsterdam, Netherlands

${ }^{2}$ Department of Medical Humanities, Amsterdam Public Health Research Institute, Vrije Universiteit Amsterdam, Amsterdam UMC, Amsterdam, Netherlands

${ }^{3}$ University Library, Vrije Universiteit Amsterdam, Amsterdam, Netherlands

${ }^{4}$ Department of Epidemiology and Biostatistics, Amsterdam Neuroscience, Vrije Universiteit Amsterdam, Amsterdam UMC, Amsterdam, Netherlands

${ }^{5}$ Department of Neurology, Massachusetts General Hospital, Harvard Medical School, Boston, MA, United States
}

\section{Corresponding Author:}

Linda MP Wesselman, MSc

Alzheimer Center Amsterdam

Department of Neurology, Amsterdam Neuroscience

Vrije Universiteit Amsterdam, Amsterdam UMC

De Boelelaan 1118

$1081 \mathrm{HZ}$

Amsterdam,

Netherlands

Phone: 31204448527

Email: 1.wesselman@vumc.nl

\section{Abstract}

Background: The number of people living with dementia is increasing worldwide, mainly because of aging of the population. To date, there is no pharmaceutical intervention to delay or treat cognitive decline or dementia. As an estimated one-third of dementia cases might be attributable to modifiable lifestyle factors (such as cognitive and physical activity), multidomain lifestyle interventions are a promising way to maintain or improve brain health. Offering programs online would enable large-scale implementation. An overview of multidomain Web-based lifestyle programs for brain health would facilitate comparison and improvement of such programs to develop effective and sustainable interventions.

Objective: This study aimed to (1) provide a comprehensive overview of Web-based multidomain lifestyle programs aimed at optimizing brain health in healthy adult populations and (2) describe the programs and targeted lifestyle factors, availability, and evaluation of adherence and user experience. In addition, a meta-analysis was performed to evaluate the effectiveness of these programs.

Methods: Electronic databases (PubMed, EMBASE, and PsycINFO) were searched for Web-based lifestyle programs that were included when the program (1) aimed to optimize brain health, (2) focused on multiple lifestyle factors, (3) was completely Web-based (website, Web application or mobile app), (4) consisted of multiple sessions, and (5) focused on a healthy adult population. Program characteristics (target population, duration, frequency, tailoring, platform, and availability) and results of program evaluations (effectiveness, user evaluations, and adherence) were extracted and compared. Studies using a controlled design were included in a random-effects meta-analysis on the effectiveness on brain health outcomes. Study quality was assessed using the physiotherapy evidence database (PEDro) scale.

Results: The electronic searches yielded 44 documents describing 14 Web-based lifestyle programs; physical and cognitive activities were targeted in all programs. Four programs $(4 / 14,29 \%)$ were publicly available and free of charge, whereas others were restricted to research settings $(5 / 14,36 \%)$, available after payment $(1 / 14,7 \%)$, or not available at all $(2 / 14,14 \%)$. User evaluations were reported for $8(57 \%)$ of the 14 programs. Reported dropout of the intervention groups ranged from $2 \%$ to $52 \%$. Overall, 3 studies evaluated the effectiveness of a program using a controlled design and were included in the meta-analysis (moderate-to-high quality). Pooled results showed a significant small-to-medium effect of the Web-based multidomain lifestyle 
interventions on outcome measures for brain health (global cognition score, subjective cognitive score, and lifestyle risk score; standard mean difference $=0.45 ; 95 \%$ CI $0.12-0.78)$, with a high degree heterogeneity across studies $\left(\mathrm{I}^{2}=75 \% ; P=.02\right)$.

Conclusions: In total, $14 \mathrm{Web}$-based multidomain lifestyle programs aimed at optimizing brain health were found. The programs showed heterogeneity in both characteristics and effectiveness evaluation. Despite this heterogeneity, this meta-analysis suggests that Web-based lifestyle programs can positively influence brain health outcomes and have the potential to contribute to the prevention of dementia.

(JMIR Ment Health 2019;6(4):e12104) doi: 10.2196/12104

\section{KEYWORDS}

meta-analysis; telemedicine; internet; lifestyle; healthy aging; cognition; dementia; health promotion; primary prevention

\section{Introduction}

\section{Background}

Dementia is characterized by a gradual decline of cognitive functioning and impairment in daily functioning [1]. Several neurodegenerative diseases can cause dementia, of which Alzheimer disease (AD) is the most common [2,3]. In 2015, 46 million people were living with dementia worldwide, and this number is estimated to increase to 131.5 million by 2050 [4] because of aging of the society [5]. Dementia causes a large burden on society and health care, with a worldwide estimated cost of $\$ 818$ billion in $2015[4,5]$.

To date, there is no pharmaceutical intervention to delay or treat cognitive decline or dementia. It is estimated that $30 \%$ of dementia cases are attributable to modifiable risk factors, including lifestyle factors such as physical activity, social activity, mood, and smoking [6-8]. Therefore, lifestyle interventions aimed at improving brain health and cognitive functioning before the onset of dementia (ie, in healthy persons) might delay or even prevent the occurrence of cognitive decline or dementia [6-9].

Studies on lifestyle interventions and cognition are mainly observational, with relatively limited evidence from large randomized trials [9]. However, evidence indicates that simultaneously targeting multiple lifestyle factors increases efficacy compared with programs focusing on a single lifestyle factor [10-12]. Furthermore, 2 nonsystematic reviews [10,13] and a systematic review with a meta-analysis [14] studied the effect of multidomain face-to-face interventions on cognitive outcomes. These latter studies reported that multidomain lifestyle interventions exerted overall positive effects on cognitive outcomes in healthy older people and in individuals with subjective cognitive decline. The Finnish Geriatric Intervention Study to Prevent Cognitive Impairment and Disability (FINGER) trial, a 2-year face-to-face multidomain intervention study (ie, diet, exercise, cognitive training, and vascular risk monitoring), demonstrated maintained global cognitive functioning in a group of participants at risk for cognitive decline, compared with a control group receiving general health advice [15].

Despite their potential, practical barriers of these face-to-face programs include the requirement of training appropriate staff and resources such as location and personnel to provide the intervention. An attractive alternative is to offer lifestyle programs online, making use of the rapidly developing landscape of electronic health (eHealth) [16]. This strategy is appealing for several reasons. First, in most countries, the majority of people have access to the internet [17], allowing them to reach larger audiences than face-to-face interventions. Second, Web-based programs have the potential to be cost-effective in the long run, with relatively low additional costs per person [18]. Third, Web-based programs might be more easily accessible at any convenient time, fitting them more easily into daily schedules and thereby increasing adherence. Finally, Web-based programs generate and collect data that can be used to automatically tailor content, for example, based on changes in lifestyle, as assessed by questionnaires. Criteria could then be set beforehand and tracked by the system. Web-based programs are easier to tailor than face-to-face programs, which need human involvement to adapt or to choose a protocol. Tailored programs improve the personal relevance of the program itself and, thus, may increase both adherence and effectiveness [19,20].

A comprehensive overview and meta-analysis of Web-based lifestyle programs for brain health is currently lacking but is required to explore the potential of these programs to benefit brain health. An overview of the programs and their evaluation might contribute to the development and implementation of more successful programs and, thereby, enable more effective and sustainable Web-based interventions.

\section{Objectives}

Therefore, this study provides an overview of Web-based multidomain lifestyle programs that aim to optimize brain health and focuses on program characteristics, current availability, evaluation of adherence, and user evaluations. In addition, a meta-analysis is performed on the effectiveness of Web-based programs on outcome measures for brain health.

\section{Methods}

\section{Search Strategy}

A systematic literature search based on the PRISMA statement was performed in collaboration with a medical librarian (LS). The databases of PubMed, EMBASE, and PsycINFO (via Ebsco) were examined from inception to June 5, 2018 (see Multimedia Appendix 1 for the full search strategy). Search terms included indexed terms from the thesaurus in PsycINFO, MeSH in PubMed, and EMtree in EMBASE as well as free-text terms. The references of the identified articles were searched for additional relevant publications. As the primary goal was 
to provide an overview of existing Web-based multidomain lifestyle programs, programs were included irrespective of the stage of their development or evaluation. Original research articles were included as well as conference abstracts, reviews, and doctoral theses mentioning (the development of) a program.

In addition, included were documents that described a program that (1) aimed to optimize brain health or cognitive functioning, as appeared from the aim of the study, program descriptions, or choice of outcome measures; (2) focused on multiple lifestyle factors; (3) was completely Web-based (website, Web application or app) and self-administered with no need for a visit to or from a health care professional; (4) consisted of multiple sessions (ie, not a single exercise); and (5) focused on a healthy adult population. Documents not available in the English language were excluded.

Furthermore, 2 independent researchers (LW and MW) screened the documents and used Covidence [21] to record the process. First, all documents were assessed for relevance based on the title and abstract. Selected documents were retrieved in full text and checked for eligibility criteria. Differences in judgment were resolved through a consensus procedure including an independent third reviewer (AH). Project websites mentioned in articles were searched for additional publications. In addition, the literature databases and Google were searched to identify additional publications on the included programs, using the name of the program and the authors. To assess availability of the identified programs, Google, Google Play Store, and Apple store were searched. If necessary, the authors were contacted for additional information, for example, regarding the availability of the program.

\section{Data Extraction}

The electronic searches yielded 11,972 documents: 3571 in PubMed, 5106 in EMBASE, and 3295 in PsycINFO. After removing duplicates, 7537 titles remained and were screened based on title and abstract; of these, 7461 were excluded. The majority of the excluded documents did not describe an intervention or a Web-based program that could be self-administered without the need for a health care professional. Of the remaining 76 studies, the full-text documents were scrutinized, applying the inclusion and exclusion criteria. The final selection for this review comprised 44 documents describing 14 Web-based lifestyle programs (see Multimedia Appendix 2 for the systematic search flowchart; see Table 1 for retrieved documents and the programs they describe).

A total of $24(24 / 44,55 \%)$ journal articles, 19 (19/44, 43\%) conference abstracts, and $1(1 / 44,2 \%)$ doctoral thesis were retrieved. Half of the journal articles (12/24; 50\%; denoted by footnote a in Table 1) were original research articles investigating $10(71 \%)$ of the 14 programs. For 4 of the programs $(4 / 14,29 \%)$, no original research article was found. Data were extracted based on program characteristics, target population, duration (length of intervention), frequency of the program (eg, number of sessions and number of modules), tailoring of content, lifestyle factors, platform of the program (website or app), current availability, and evaluation of the program.

\section{Evaluation of Web-Based Multidomain Lifestyle Programs}

\section{Effectiveness}

Results of studies that used a controlled design were pooled to perform a meta-analysis on the effectiveness of Web-based multidomain lifestyle programs on outcome measures relevant for brain health or cognitive functioning. This resulted in a meta-analysis including 3 studies entitled Body Brain Life [23], Keep your brain fit [53], and Long Lasting Memories [58]. For these studies, 2 raters (LW and $\mathrm{AH}$ ) assessed the study quality and risk of bias using the physiotherapy evidence database (PEDro) scale [65-67]. The PEDro scale evaluates the internal validity by assessing the eligibility criteria, allocation, blinding and reporting of outcome measures, between-group comparisons, and variability. For this review, we deemed the PEDro item blinding of therapists not to be applicable, as interventions were provided as self-administered on the internet and not by therapists.

\section{User Evaluations}

During the development and evaluation of Web-based interventions, the involvement of users for evaluation of user experience and usability is important; however, discussion continues as to what these terms exactly entail [68]. We based our definitions on the International Organization of Standardization (ISO) guidelines (ISO 9241-2010, ISO/ICE 25010) and selected parts of the guidelines to summarize the extracted information. First, user experience includes all the users' emotions, beliefs, preferences, perceptions, physical and psychological responses, behaviors, and accomplishments that occur before, during, and after use of the Web-based program. Second, we defined usefulness as the users' perception on whether the program served their needs and purpose and was helpful in any way. Finally, usability was defined as whether the program was convenient and easy to use, taking into account the technical aspects of the platform. For each study, we assessed whether our definitions of user experience, usefulness, or usability were described. Subsequently, we indicated whether methods used for this evaluation were clearly described, by defining whether it would be possible to replicate the design. Qualitative debriefing or survey with open question were deemed not specific enough, whereas specific questionnaire items that were used to collect information on user experience were deemed sufficient.

\section{Adherence}

Assessing adherence to the usage of an eHealth technology can be challenging, as also noted in a recent review [69]. However, because the majority of the programs in this review did not describe the intended use of the program, it was not possible to assess usage adherence (ie, not in terms of number of log-ins or time spent). Therefore, adherence was assessed as the percentage of participants completing the intervention and postintervention measurement or in relation to the number of participants that started the intervention. 
Table 1. Characteristics of the 14 included Web-based lifestyle programs.

\begin{tabular}{|c|c|c|c|c|c|}
\hline Number & $\begin{array}{l}\text { Program (acronym } \\
\text { and full name) }\end{array}$ & Target population & Program characteristics & $\begin{array}{l}\text { Website or } \\
\text { app }\end{array}$ & Availability \\
\hline 1 & $\begin{array}{l}\text { Body Brain Life: } \\
{[22]+[23]^{\mathrm{a}}}\end{array}$ & $\begin{array}{l}\text { Nonsymptomatic } \\
\text { adults at risk for } \\
\text { Alzheimer disease }\end{array}$ & $\begin{array}{l}\text { Duration: } 12 \text { weeks; number of sessions: } 12 \text {; frequency: } \\
\text { 1/week; and tailored: yes, Lifestyle- } Q^{\text {b }}\end{array}$ & Website & $\begin{array}{l}\text { Available: yes; pub- } \\
\text { lic: no }\end{array}$ \\
\hline 2 & $\begin{array}{l}\text { Brain Aging Moni- } \\
\text { tor }[24,25]+[26]^{\mathrm{a}}\end{array}$ & $\begin{array}{l}\text { Dutch workforce } \\
\text { and general popula- } \\
\text { tion }\end{array}$ & $\begin{array}{l}\text { Duration: } 52 \text { weeks; number of sessions:- }{ }^{c} \text {; frequen- } \\
\text { cy:- ; tailored: yes, Lifestyle-Q and goals set }\end{array}$ & Website & Available: no \\
\hline 3 & $\begin{array}{l}\text { Brainy app }[27,28] \\
+[29]^{\mathrm{a}}\end{array}$ & General population & $\begin{array}{l}\text { Duration: } 4 \text { weeks; number of sessions: —; frequency: } \\
\text { —; tailored: yes, Lifestyle-Q }\end{array}$ & $\begin{array}{l}\text { iOS app and } \\
\text { Android app }\end{array}$ & $\begin{array}{l}\text { Available: yes; pub- } \\
\text { lic: yes; Free of } \\
\text { charge: yes Link }\end{array}$ \\
\hline 4 & $\begin{array}{l}\text { Brain-Heart Health } \\
\text { Plus program } \\
{[27,28]+[29]^{\mathrm{a}}}\end{array}$ & General population & $\begin{array}{l}\text { Duration: } 4 \text { weeks; number of sessions:-; frequency:-—; } \\
\text { tailored: yes, Lifestyle-Q }\end{array}$ & Website & $\begin{array}{l}\text { Available: yes; but } \\
\text { redesigned format; } \\
\text { public: yes; free of } \\
\text { charge: yes Link }\end{array}$ \\
\hline 5 & $\begin{array}{l}\text { DoReMi: Decrease } \\
\text { of cOgnitive decline, } \\
\text { malnutRition and } \\
\text { sedEntariness by el- } \\
\text { derly empowerment } \\
\text { in lifestyle Manage- } \\
\text { ment and social In- } \\
\text { clusion [30,31] }\end{array}$ & $\begin{array}{l}\text { General population, } \\
\text { elderly }\end{array}$ & $\begin{array}{l}\text { Duration: } 13 \text { weeks; number of sessions: } 36 \text {; frequency: } \\
\text { 3/week; tailored: yes, acquired data }\end{array}$ & Android app & Available: No \\
\hline 6 & $\begin{array}{l}\text { Gray Matters } \\
{[32-34]+[35]^{\mathrm{a}}}\end{array}$ & General population & $\begin{array}{l}\text { Duration: } 26 \text { weeks; number of sessions: —; frequency: } \\
\text { —; tailored: yes; and Lifestyle-Q }\end{array}$ & $\begin{array}{l}\text { iOS app and } \\
\text { Android app }\end{array}$ & $\begin{array}{l}\text { Available: yes; pub- } \\
\text { lic: no }\end{array}$ \\
\hline 7 & $\begin{array}{l}\text { HATICE: Healthy } \\
\text { Aging Through Inter- } \\
\text { net Counselling in } \\
\text { the Elderly } \\
{[12,36-47]+} \\
{[48,49]^{\mathrm{a}}}\end{array}$ & $\begin{array}{l}\text { Elderly with cardio- } \\
\text { vascular risk factors, } \\
\text { cardiovascular dis- } \\
\text { ease or diabetes } \\
\text { mellitus }\end{array}$ & $\begin{array}{l}\text { Duration: } 78 \text { weeks; number of sessions: —; frequency: } \\
\text { 1/week; tailored: yes, goals and topic interest }\end{array}$ & Website & $\begin{array}{l}\text { Available: yes; pub- } \\
\text { lic: no }\end{array}$ \\
\hline 8 & $\begin{array}{l}\text { InMINDD: INnova- } \\
\text { tive, Midlife INter- } \\
\text { vention for Demen- } \\
\text { tia Deterrence } \\
{[50,51]}\end{array}$ & $\begin{array}{l}\text { Individuals with } 1 \\
\text { modifiable risk fac- } \\
\text { tor based on } \\
\text { Lifestyle for Brain } \\
\text { Health (LIBRA) } \\
\text { score [52] }\end{array}$ & $\begin{array}{l}\text { Duration: } 26 \text { weeks; number of sessions: - ; frequency: } \\
- \text {; tailored: yes, demographic, health behavior, and } \\
\text { clinical information }\end{array}$ & Website & $\begin{array}{l}\text { Available: yes; pub- } \\
\text { lic: no }\end{array}$ \\
\hline 9 & $\begin{array}{l}\text { Keep your brain fit } \\
{[53]^{\mathrm{a}}}\end{array}$ & General population & $\begin{array}{l}\text { Duration: } 4 \text { weeks; number of sessions: —; frequency: } \\
\text { —; tailored: yes, Lifestyle and cognition monitor' }\end{array}$ & Website & $\begin{array}{l}\text { Available: yes; pub- } \\
\text { lic: yes; free of } \\
\text { charge: yes Link }\end{array}$ \\
\hline 10 & $\begin{array}{l}\text { LEAP: Lifestyle En- } \\
\text { richment for } \\
\text { Alzheimer Preven- } \\
\text { tion }[54]^{\text {a }}\end{array}$ & $\begin{array}{l}\text { Individuals with up- } \\
\text { coming retirement }\end{array}$ & $\begin{array}{l}\text { Duration: } 8 \text { weeks; number of sessions: —; frequency: } \\
\text { —; tailored: yes, Lifestyle-Q and Goals }\end{array}$ & Website & $\begin{array}{l}\text { Available: yes; pub- } \\
\text { lic: yes; free of } \\
\text { charge: yes Link }\end{array}$ \\
\hline 11 & $\begin{array}{l}\text { Long Lasting Memo- } \\
\text { ries }[13,55-57]+ \\
{[58,59]^{\mathrm{a}}}\end{array}$ & $\begin{array}{l}\text { Older adults with or } \\
\text { without neurocogni- } \\
\text { tive disorders }\end{array}$ & $\begin{array}{l}\text { Duration: } 10 \text { weeks; number of sessions: } 24 \text {; frequency: } \\
\text { 4/week; tailored: yes, patient group }\end{array}$ & $\begin{array}{l}\text { Website }+ \\
\text { Android or } \\
\text { iOS app for } \\
\text { cognitive } \\
\text { component }\end{array}$ & $\begin{array}{l}\text { Available: yes; pub- } \\
\text { lic: no; free of } \\
\text { charge: no; physical } \\
\text { component: } € 100 / 6 \\
\text { months, cognitive } \\
\text { component: } € 100 / 6 \\
\text { months Link }\end{array}$ \\
\hline 12 & $\begin{array}{l}\text { Maintain your brain } \\
{[60,61]}\end{array}$ & $\begin{array}{l}\text { Adults with } 2 \text { risk } \\
\text { factors for dementia }\end{array}$ & $\begin{array}{l}\text { Duration: } 208 \text { weeks ( } 4 \text { years); number of sessions: } \\
\text { (4x10-week modules in the first year); frequency: - } \\
\text { tailored: yes, current lifestyle }\end{array}$ & - & $\begin{array}{l}\text { Available: Yes; pub- } \\
\text { lic: no }\end{array}$ \\
\hline 13 & Smart Aging [62] & $\begin{array}{l}\text { General population, } \\
\text { seniors }\end{array}$ & $\begin{array}{l}\text { Duration: } 16 \text { weeks; number of sessions: —; frequency: } \\
\text { 7/week; and tailored: - }\end{array}$ & - & - \\
\hline
\end{tabular}




\begin{tabular}{|c|c|c|c|c|c|}
\hline Number & $\begin{array}{l}\text { Program (acronym } \\
\text { and full name) }\end{array}$ & Target population & Program characteristics & $\begin{array}{l}\text { Website or } \\
\text { app }\end{array}$ & Availability \\
\hline 14 & $\begin{array}{l}\text { Vital Aging Program } \\
\text { (e-learning version) } \\
{[63,64]^{\mathrm{a}}}\end{array}$ & $\begin{array}{l}\text { Population based } \\
\text { (students from uni- } \\
\text { versity programs for } \\
\text { older adults) }\end{array}$ & $\begin{array}{l}\text { Duration: } 13 \text { weeks; number of sessions: —; frequency: } \\
\text { 1/week; and tailored: - }\end{array}$ & Website & - \\
\hline
\end{tabular}

${ }^{\mathrm{a}}$ Original research articles.

${ }^{\mathrm{b}}$ Lifestyle-Q: Lifestyle Questionnaire.

${ }^{\mathrm{c}}$ Information that was not specified.

\section{Statistical Analysis and Meta-Analysis}

IBM SPSS Statistics (version 22) [70] was used to calculate descriptive statistics to summarize program characteristics. For the studies that assessed effectiveness, postintervention means, SDs, and group size were pooled. We used the results that were reported for the primary outcome measure that assessed brain health or cognitive functioning (ie, objective and subjective measures). Results were inverted if necessary, making higher scores represent better scores. Review Manager (version 5.3, The Cochrane Collaboration, Copenhagen, Denmark) was used to perform a random-effects meta-analysis. The overall effect of lifestyle interventions on brain health outcomes was estimated, and the results were presented as a forest plot. The Cochrane $\mathrm{X}^{2}$ was used to test for heterogeneity across the included articles, with a $P<.05$ indicative of heterogeneity. The $\mathrm{I}^{2}\left(100 \times\left(\mathrm{X}^{2}-\mathrm{df} / \mathrm{X}^{2}\right)\right.$ [71] was used to measure the degree of heterogeneity (25\%, low; 50\%, moderate; and 75\%, high [72]).

\section{Preferred Reporting Items for Systematic Reviews and Meta-Analysis Statement}

As the scientific output in this field is somewhat limited, not all the items of the Preferred Reporting Items for Systematic Reviews and Meta-Analysis (PRISMA) statement were deemed applicable. Information that contributed to the aim of this review is reported and includes the characteristics, availability, and evaluation.

\section{Results}

\section{Characteristics of the Web-Based Multidomain Lifestyle Programs}

Table 1 provides an overview of the 14 included Web-based lifestyle programs (with full names and their characteristics). Overall, 8 programs $(8 / 14,57 \%)$ were developed for a general adult population (Brain Aging Monitor [24], Brainy app [29], Brain-Heart Health Plus Program [29], Decrease of cOgnitive decline, malnutRition and sedEntariness by elderly empowerment in lifestyle Management and social Inclusion (DoReMi) [30], Gray Matters [35], Keep your brain fit [53], Smart Aging [62], and Vital Aging program [63]). In addition, 6 programs $(6 / 14,43 \%)$ described a more specific target population: Body Brain Life [22] and Maintain your Brain [60] focused on nonsymptomatic adults at risk of AD, Healthy Aging
Through Internet Counselling in the Elderly (HATICE) [36] targets elderly with cardiovascular risk factors and cardiovascular disease, and INnovative, Midlife INtervention for Dementia Deterrence (InMINDD) [50] targets individuals with 1 modifiable risk factor. The Lifestyle Enrichment for Alzheimer Prevention (LEAP) [54] program was developed for individuals with upcoming or recent retirement and Long Lasting Memories [58] for individuals with or without a cognitive impairment.

The programs were offered on a website $(8 / 14,57 \%$ $[22,24,29,36,50,53,54,63])$, a mobile app $(3 / 14 ; 21 \%[29,30,35])$, or both $(1 / 14,7 \%$ [55]), whereas the platform was not specified for the remaining $2[60,62]$. Only $4(4 / 14,29 \%)$ programs were available publicly and free of charge $[29,53,54]$. Overall, 5 programs $(5 / 14,36 \%)$ were available within a research setting [22,35,36,50,60] and $1(1 / 14,7 \%)$ after payment [58]. In addition, 2 programs $(2 / 14,14 \%)$ were not available online at all $[25,30]$, and for 2 programs $(2 / 14,14 \%)$, it was not clear whether they were still available [62,63]. Mean intervention duration was 33.9 (SD 54.1; range 4-204) weeks. Furthermore, 3 programs [22,30,55] specified the total number of sessions (mean 24, [SD 12]; range 12-36 sessions), and 6 programs $[22,30,36,55,62,63]$ indicated a frequency per week (mean 2.8 [SD 2.4]; range 1-7 sessions/week). For the remaining programs, the number of sessions and the frequency per week were flexible.

Most programs tailored the content of the program to previously acquired information. Content was mainly tailored based on current lifestyle (eg, assessed with a questionnaire on lifestyle and risk factors; 9/14, 64\% [22,24,29,35,36,50,53,60]). Furthermore, 3 programs $(3 / 14,21 \%$; [25,36,54]) additionally tailored content based on goals that were set within the program, and 2 programs $(2 / 14,14 \%$; [62,63]) did not specify information on tailoring. The number of lifestyle factors targeted in the programs ranged from 2 [58] to 9 [60] (Table 2). In short, all interventions targeted a physical and a cognitive component. Furthermore, most programs included a nutritional component (13/14 programs, 93\%; all except Long Lasting Memories [58]) as well as a social component (10/14 programs, 71\%; $[22,29,30,35,50,53,54,62,63])$. Half of the programs included smoking cessation $(7 / 14,50 \%$; $[24,29,36,50,60,62])$, and other factors included alcohol intake, vascular risk factors, stress management, sleep, and mood. 
Table 2. Lifestyle factors targeted in the included programs. Per row, the factors per program are presented. Per column, the programs including this specific lifestyle factors are presented.

\begin{tabular}{|c|c|c|c|c|c|c|c|c|c|c|c|}
\hline Program & Physical & Cognitive & Nutrition & Social & Smoke & Vascular $^{\mathrm{a}}$ & Alcohol & Stress & Sleep & Mood & Other $^{\mathrm{b}}$ \\
\hline Body Brain Life & $x^{c}$ & $\mathrm{x}$ & $\mathrm{x}$ & $\mathrm{x}$ & - & - & - & - & - & - & $\mathrm{x}$ \\
\hline Brain Aging Monitor & $\mathrm{x}$ & $\mathrm{x}$ & $\mathrm{x}$ & - & $\mathrm{x}$ & - & $\mathrm{x}$ & $\mathrm{x}$ & $\mathrm{x}$ & - & - \\
\hline Brainy app & $\mathrm{x}$ & $\mathrm{x}$ & $\mathrm{x}$ & $\mathrm{x}$ & $\mathrm{x}$ & $\mathrm{x}$ & $\mathrm{x}$ & - & - & - & - \\
\hline Brain Heart Health Plus Program & $\mathrm{x}$ & $\mathrm{x}$ & $\mathrm{x}$ & $\mathrm{x}$ & $\mathrm{x}$ & $\mathrm{x}$ & $\mathrm{x}$ & - & - & - & - \\
\hline $\begin{array}{l}\text { Decrease of cOgnitive decline, } \\
\text { malnutRition and sedEntariness } \\
\text { by elderly empowerment in } \\
\text { lifestyle Management and social } \\
\text { Inclusion }\end{array}$ & $\mathrm{x}$ & $\mathrm{x}$ & $\mathrm{x}$ & $\mathrm{x}$ & - & - & - & - & - & - & - \\
\hline Gray Matters & $\mathrm{x}$ & $\mathrm{x}$ & $\mathrm{x}$ & $\mathrm{x}$ & - & - & - & $\mathrm{x}$ & $\mathrm{x}$ & - & - \\
\hline $\begin{array}{l}\text { Healthy Aging Through Internet } \\
\text { Counseling in the Elderly }\end{array}$ & $\mathrm{x}$ & $\mathrm{x}$ & $\mathrm{x}$ & - & $\mathrm{x}$ & $\mathrm{x}$ & - & - & - & - & - \\
\hline $\begin{array}{l}\text { INnovative, Midlife INtervention } \\
\text { for Dementia Deterrence }\end{array}$ & $\mathrm{x}$ & $\mathrm{x}$ & $\mathrm{x}$ & $\mathrm{x}$ & $\mathrm{x}$ & $\mathrm{x}$ & $\mathrm{x}$ & - & - & $\mathrm{x}$ & - \\
\hline Keep your brain fit & $\mathrm{x}$ & $\mathrm{x}$ & $\mathrm{x}$ & $\mathrm{x}$ & - & - & - & $\mathrm{x}$ & $\mathrm{x}$ & $\mathrm{x}$ & - \\
\hline $\begin{array}{l}\text { Lifestyle Enrichment for } \\
\text { Alzheimer Prevention }\end{array}$ & $\mathrm{x}$ & $\mathrm{x}$ & $\mathrm{x}$ & $\mathrm{x}$ & - & - & - & - & - & - & $\mathrm{x}$ \\
\hline Long Lasting Memories & $\mathrm{x}$ & $\mathrm{x}$ & - & - & - & - & - & - & - & - & - \\
\hline Maintain your brain & $\mathrm{x}$ & $\mathrm{x}$ & $\mathrm{x}$ & - & $\mathrm{x}$ & $\mathrm{x}$ & $\mathrm{x}$ & $\mathrm{x}$ & $\mathrm{x}$ & $\mathrm{x}$ & - \\
\hline Smart Aging & $\mathrm{x}$ & $\mathrm{x}$ & $\mathrm{x}$ & $\mathrm{x}$ & $\mathrm{x}$ & $\mathrm{x}$ & - & - & - & - & - \\
\hline Vital Aging Program & $\mathrm{x}$ & $\mathrm{x}$ & $\mathrm{x}$ & $\mathrm{x}$ & - & - & - & - & - & $\mathrm{x}$ & $\mathrm{x}$ \\
\hline $\begin{array}{l}\text { Total number of programs target- } \\
\text { ing the lifestyle factor }\end{array}$ & 14 & 14 & 13 & 10 & 7 & 6 & 5 & 4 & 4 & 4 & 3 \\
\hline
\end{tabular}

${ }^{a}$ Vascular: this category summarized vascular and physical variables often used in vascular risk management, for example, blood pressure and weight. ${ }^{\mathrm{b}}$ Other factors included were for Body Brain Life: dementia literacy, dementia risk factors, and health self-management; for Lifestyle Enrichment for Alzheimer Prevention: time management, and for Vital Aging Program: body caring.

${ }^{\mathrm{c}}$ Per column it is indicated whether a program does $(\mathrm{x})$ or does not (-) include the specific lifestyle factors.

\section{Evaluation of Web-Based Multidomain Lifestyle Programs}

\section{Effectiveness, Study Quality, and Meta-Analysis}

Effectiveness was measured on a range of brain health outcomes, such as an AD risk questionnaire (eg, lifestyle factors associated with the development of AD such as food intake or level of physical activity), cognitive test performance, and the subjective experience of cognitive problems. Table 3 presents an overview of the outcome measures.

For 4 programs $(4 / 14,29 \%)$, effectiveness was evaluated, of which $3(3 / 14,21 \%)$ used a controlled design. The latter 3 were included in the meta-analysis: Body Brain Life [23], Keep your brain fit [53], and Long Lasting Memories [58] (not included $[26,59])$. On the PEDro scale, the quality of the studies ranged from moderate (5/10 [58]) to high (8/10 [23]; Table 4). All 3 studies specified recruitment of participants and eligibility criteria. At baseline, the experimental groups were comparable with the control groups. In addition, all used an intention-to-treat analysis and reported between-group comparisons as well as point estimates with measures of variability. Points were lost on the PEDro items for randomization, blinding of subjects and assessors, and the cutoff of $85 \%$ of participants completing follow-up measurement. 
Table 3. Outcome measures. The outcome measures per study are shown, as described in the retrieved documents. If authors delineated primary and secondary outcome measures, this is indicated in the column Priority. For primary outcome measures, the specific outcome measure is described.

\begin{tabular}{llll}
\hline Program & Priority & Outcome measure per domain & Specific outcome measure \\
\hline Body Brain Life & Primary & Lifestyle-risk factors-Q ${ }^{\mathrm{a}}$ & $\begin{array}{l}\text { ANU Alzheimer's Disease Risk Index (ANU- } \\
\text { ADRI) [73] }\end{array}$
\end{tabular}

Body Brain Life

Secondary

Brain Aging Monitor

Primary

Brain Aging Monitor

Secondary

Brainy app + Brain-Heart Health

Plus program (not prioritized)

Decrease of cOgnitive decline, malnutRition and sedEntariness by elderly empowerment in lifestyle Management and social Inclusion (not prioritized)

Gray matters

Primary

Gray matters

Secondary

Healthy Aging Through Internet Counselling in the Elderly

Healthy Aging Through Internet Counselling in the Elderly

INnovative, Midlife INtervention for Dementia Deterrence

INnovative, Midlife INtervention for Dementia Deterrence

Keep your brain fit

Primary

Keep your brain fit

Secondary

Lifestyle Enrichment for Alzheimer Primary Prevention

Primary

Secondary

Primary

Secondary
Cognition: objective; body measurements; other: dementia recognition, and dementia knowledge

Cognition: objective; Lifestyle-risk factors-Q; and Goal setting

Body measurements and other: change in selfefficacy and change in self-control

Lifestyle-risk factors-Q and other: Dementia risk reduction knowledge and attitudes to changing behavior

Cognition: objective; Lifestyle: measurement and Body measurements

Body measurements and Lifestyle-risk factorsQ

Cognition: subjective

Lifestyle-risk factors-measurement; cognition: objective; other: mood and psychological stress; metacognition, intrinsic motivation; readiness to change, sleep quality; and social engagement, couple satisfaction

Body measurements

Body measurements; lifestyle-risk factors-Q; cognition: objective; clinical measurement; goal setting; other: mood, cost-effectiveness

Lifestyle-risk factors-Q

Lifestyle-risk factors-Q

Cognition: objective; other: Depression, anxiety, stress, Self-rated health, Feelings of loneliness, Difficulties in recovering from work, General health, and $\mathrm{QoL}^{\mathrm{d}}$

Lifestyle-risk factors: measurements $-b$

BAM-COG games [74] Lifestyle score (including physical activity, nutrition, and sleep) [24]

Not specified; 10 factors (risk/protective for dementia); eg, motivation to reduce dementia risk

Montreal Cognitive Assessment (MoCA) [75], Token test [76]; Mini Nutritional Assessment (MNA) (version not specified) [77]; $\mathrm{BMI}^{\mathrm{c}}$, waist-to-hip ratio, waist and arm circumference, and blood pressure related to the 6-min walk test

BMI, blood pressure, blood biomarkers including physical and cognitive activity, nutrition (Diet History Questionnaire + DASH score), sleep, social engagement, and stress

Composite score (systolic. blood pressure, lowdensity lipoprotein, and BMI)

\author{
$-$
}

Lifestyle for Brain Health (LIBRA) score [52]

Subj cognitive functioning (MIA) [78], cognitive failure (CFQ; $[79,80])$, Self-evaluative questions [81]

Dietary intake [82] and physical activity (accelerometry); weight, BMI, waist circumference, body fat mass, fat-free mass, today body water, body weight, and waist circumference; and cognition, physical capability, physiological, and psychosocial well-being

Body measurements; Battery of Healthy aging _ phenotype (HAP) measurements; and other

Body measurements; cognition: objective; Lifestyle-risk factors-Q; and other: mood, Quality of Life, IADL
Physical fitness (composite score Senior fitness test); eg, Mini Mental State Examination, MoCA, Trail Making Test, California Verbal Learning Test; and Social Life Questionnaire 


\begin{tabular}{llll}
\hline Program & Priority & Outcome measure per domain & Specific outcome measure \\
\hline Maintain your brain & Primary & Cognition and clinical measurement & Unspecified and Dementia incidence \\
Maintain your brain & Secondary & $\begin{array}{l}\text { Lifestyle-risk factors-Q; goal setting; clinical } \\
\text { measurements; and medication }\end{array}$ & - \\
Smart Aging & - & Other: QoL & - \\
Vital Aging Program (e-learning) & - & $\begin{array}{l}\text { Other: reported changes and intended future } \\
\text { changes }\end{array}$ & -
\end{tabular}

${ }^{\mathrm{a}} \mathrm{Q}$ : Questionnaire.

${ }^{\mathrm{b}}$ Information either not available (priority) or not specified (secondary outcome measures).

${ }^{\mathrm{c}} \mathrm{BMI}$ : body mass index.

${ }^{\mathrm{d}}$ QoL: quality of life.

Table 4. Quality assessment of pooled studies. This table presents the quality and bias assessment of the studies that were pooled in the meta-analysis, based on the physiotherapy evidence database scale (PEDro). Blinding of therapist was deemed not applicable for all 3 studies, as the interventions were offered by automated systems. Concealed allocation was deemed not applicable for Long Lasting Memories, as participants were not randomized. Blinding of assessors was deemed for Keep your brain fit, as the assessment was conducted within the Web-based system.

\begin{tabular}{|c|c|c|c|}
\hline Items & Body Brain Life [23] & Keep your brain fit [53] & Long Lasting Memories [58] \\
\hline Eligibility criteria and source specified & $+^{\mathrm{a}}$ & + & + \\
\hline Random allocation & + & + & $-b$ \\
\hline Concealed allocation & + & - & $\mathrm{N} / \mathrm{A}^{\mathrm{c}}$ \\
\hline Baseline comparability & + & + & + \\
\hline Blinding of subjects & - & - & - \\
\hline Blinding of therapists & N/A & N/A & N/A \\
\hline Blinding of assessors & + & N/A & - \\
\hline More than $85 \%$ follow-up & - & - & - \\
\hline Intention-to-treat analysis & + & + & + \\
\hline Reporting of between-groups statistical comparisons & + & + & + \\
\hline Reporting of point measures and measures of variability & + & + & + \\
\hline Total PEDro score $0-10$ & 8 & 6 & 5 \\
\hline
\end{tabular}

${ }^{\mathrm{a} C}$ Criteria fulfilled.

${ }^{\mathrm{b}}$ Criteria not fulfilled or it was unclear whether criteria were fulfilled.

${ }^{\mathrm{c}}$ Criteria not applicable.

Directly after the intervention, participants of Body Brain Life [23] showed no significant reduction in risk for AD compared with the control group. However, at 26-week follow-up, the intervention group showed a significant reduction in risk compared with the control group (intervention group mean score pretest $=-1.07$ [SD 0.72], posttest $=-3.63$ [SD 0.77]; control group pretest $=-1.38$ [SD 0.70], posttest $=-1.93$ [SD 0.73]; beta: -.37 , SE $0.16, P=.05$ ). This result was mainly because of an increase in protective lifestyle behaviors and not because of a decrease in risk factors, such as smoking or high cholesterol. For Keep your brain fit [53], there was a significant effect of group on perceived change in memory functioning (intervention group mean score pretest $=29.99$ [SD 6.22], posttest $=31.46$ [SD 6.06]; control group pretest $=28.97$ [SD 7.50], posttest $=30.17$ [SD 7.05]; $P=.007$ ), showing a small effect (Cohen $d=.20$ ). Moreover, a significant effect of group was found on a cognitive failure questionnaire (intervention group mean score pretest $=66.15$ [SD 11.36]; posttest $=65.85$ [SD 10.30]; control group pretest $=63.76$ [SD 11.98], posttest $=65.11$ [SD 12.25]; $P=.03$ ); however, this could be explained by baseline group differences. There was no significant effect of group on perceived memory capacity. Compared with an active control group, the participants of Long Lasting Memories [58] showed a significant improvement in global cognition $\left(t_{219}=3.2 ; P=.002\right)$, with a medium effect (Cohen $d=.31$ ). The cognitive status of the participants of Long Lasting Memories ranged from healthy to dementia, and exploratory analysis in the effectiveness study [58] indicated that the effect did not differ for the different diagnostic groups; therefore, this latter study is included in the meta-analysis, despite the inclusion of cognitively impaired participants. 
Figure 1. Forest plot meta-analysis. This figure presents the results of the random-effect meta-analysis that included data from 3 effectiveness studies using a controlled design. Outcome measures were measures for brain health (Body Brain Life: ANU Alzheimer's Disease Risk Index and lifestyle risk score; Keep your brain fit: Meta Memory in Adulthood scale and subjective cognitive functioning, and Long Lasting Memories: Mini Mental State Examination and global cognition score). Duration of the interventions: Body Brain Life, 12 weeks; Keep your brain fit, 4 weeks; Long Lasting Memories, variable, with an average of 6 weeks.

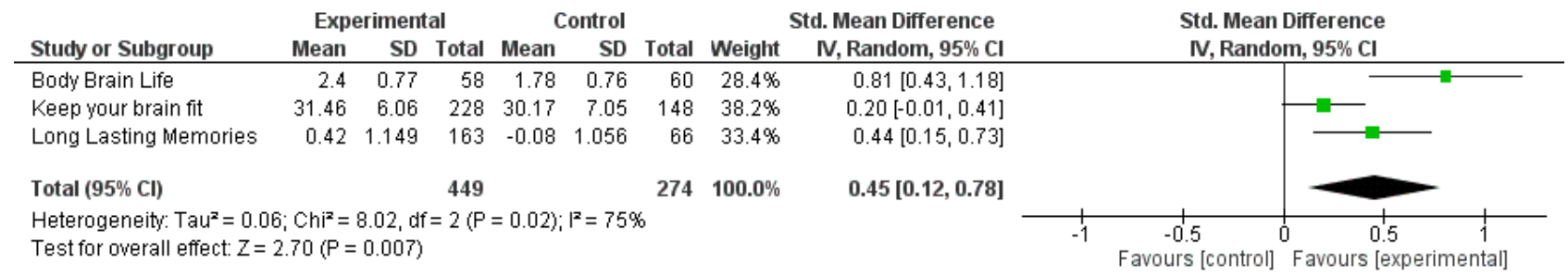

Results of these 3 studies were pooled in a meta-analysis, combining a lifestyle risk score (ANU Alzheimer's Disease Risk Index Questionnaire [73] for Body Brain Life [23]), a subjective cognitive measure (Meta memory in Adulthood Questionnaire [78] for Keep your brain fit [53]), and a global cognitive measure (Mini Mental State Examination [83] for Long Lasting Memories [58]). Pooled results (see Figure 1) showed a significant overall small-to-medium effect of the Web-based multidomain lifestyle interventions on outcome measures for brain health or cognitive functioning in the intervention group compared with the control group (standardized mean difference $[\mathrm{SMD}]=0.45 ; 95 \%$ CI $0.12-0.78)$. The degree of heterogeneity across studies was high $\left(\mathrm{I}^{2}=75 \% ; P=.02\right)$.

\section{User Evaluations}

For 8 programs $(8 / 14,57 \%), 10$ studies [29,32,35,36, $48,49,53,54,62,63]$ reported user evaluations: all 10 reported results on usability and $7(7 / 14,50 \%)$ also reported results on usefulness and usability (for evaluations see Table 5). The methods to evaluate user experiences, usefulness, and usability were qualitative debriefing, a survey, Likert scales ranging from 0 to 10 for specific topics (eg, satisfaction and simplicity), and the percentage of participants that reported the program to be usable and user-friendly. User evaluations offered input regarding content and technical features to improve the Web-based multidomain lifestyle programs. Overall, the programs were evaluated as usable. In general, the reported barriers were mainly technical, such as password setting and navigation method. In addition, 2 studies evaluating the user-based concepts of 3 programs described their methods clearly and in a reproducible way [29,54]. In 1 study, the Brain Heart Health Plus Program and the Brainy app were compared directly [35]. Most participants evaluated both programs as overall positive and reported that the information was interesting, easy to understand, easy to navigate, and insightful. Users of the Brain Heart Health Plus Program website were more positive than users of the app, which the authors attributed to the difference in platform and the lack of instructions on how to use the app.

In their evaluation of LEAP [54], participants rated the modules on physical activity, social activity, and eating well as the highest; design, navigation, and technical issues were problematic for a few users.
The other 5 programs described results of user evaluations using a variety of methods: a few representative findings are presented here. Participants of Gray Matters [32,35] used the app regularly, with on average 3 app launches per week, and ranked 6 behavioral domains in order of importance: physical activity, cognitive stimulation, healthy food choices, stress management, sleep quality, and social engagement. Participants of HATICE $[36,49]$ provided input on the password difficulty and deemed an instruction video necessary. Interactive features and healthy lifestyle content were valued, and participants liked to print the content. Using interviews, user-friendliness, usefulness, and perceived benefit were identified as important factors for initial use. Expectation of, and experience with lifestyle changes, and incorporation into daily routine were deemed important for sustained platform use [48]. Participants of Keep your brain fit [53] evaluated the program with a mean score of 7.3 (SD 1.09) out of $10(n=228)$. Most recommendations for improving the intervention were technical (eg, more time to complete the intervention or more reminders) or content related (better explanation of the concepts). For the Vital Aging Program, most participants reported that the course was interesting, expectations were sufficiently met, and the content was helpful to improve their daily living $(95.8 \%, 94 \%$, and $96 \%$, respectively) [63].

\section{Adherence and Dropout}

Overall, 6 studies included data on adherence to the intervention period [23,26,29,53,54,58]. In total, $1455(1455 / 3598,40.44 \%)$ participants dropped out of the active programs before completing the intervention period and postintervention measurement (mean 243 [SD 473.9]; range 1-1205 participants). The high dropout rate was mainly because of the study on the Brain Aging Monitor [26] (1205/2305, 52,27\%). Excluding this study, a total of $250(250 / 1293,19.33 \%)$ participants dropped out (mean 50 [SD 53.4]; range 1-128 participants). The dropout rates of the intervention group of the other studies were $2 \%$ (1/58; Body Brain Life [23]), 10.8\% (45/415; Brainy app and Brain Heart Health Plus program combined [29]), 36.0\% (128/356; Keep your brain fit [53]), 4\% (2/50; LEAP [54]), and $31.2 \%$ (74/237; Long Lasting Memories [58]). Reported reasons for dropping out were time constraints, dissatisfaction with the content, family issues, and physical illness. Dropouts were younger, had a higher education level, were more likely to work full time, and had a job that required mental and physical activity $[29,53]$. The other programs found no differences between the completers and noncompleters. 
Table 5. User evaluations. This table shows whether the concepts of user experience, usefulness, and usability were evaluated and whether the evaluation methods were clearly described. For definitions, see Methods section User Evaluations.

\begin{tabular}{|c|c|c|c|}
\hline Program & User experience & Usefulness & Usability \\
\hline Body Brain Life & $-{ }^{\mathrm{a}}$ & - & - \\
\hline Brain Aging Monitor & - & - & - \\
\hline Brainy app [29] & $+{ }^{b}$ & + & + \\
\hline Brain Heart Health Plus Program [29] & + & + & + \\
\hline $\begin{array}{l}\text { Decrease of cOgnitive decline, malnutRition and sedEntariness by elderly empowerment } \\
\text { in lifestyle Management and social Inclusion }\end{array}$ & - & - & - \\
\hline Gray Matters [32,35] & - & $\sim \mathrm{c}$ & $\sim$ \\
\hline Healthy Aging Through Internet Counselling in the Elderly $[36,48,49]$ & + & + & $\sim$ \\
\hline INnovative, Midlife INtervention for Dementia Deterrence & - & - & - \\
\hline Keep your brain fit [53] & $\sim$ & - & $\sim$ \\
\hline Lifestyle Enrichment for Alzheimer Prevention [54] & + & + & + \\
\hline Long Lasting Memories & - & - & - \\
\hline Maintain your brain & - & - & - \\
\hline Smart Aging [62] & $\sim$ & $\sim$ & $\sim$ \\
\hline Vital Aging Program [63] & $\sim$ & $\sim$ & $\sim$ \\
\hline
\end{tabular}

${ }^{\mathrm{a}}$ User-based concepts were not evaluated or it was unclear whether the concepts were evaluated.

${ }^{\mathrm{b}}$ Results were described and methods were specified.

${ }^{\mathrm{c}}$ Results were described but methods were unspecified.

\section{Discussion}

\section{Principal Findings}

In this systematic review of Web-based multidomain lifestyle programs, 14 programs that aimed to optimize brain health were found. Comparison of these programs showed strong heterogeneity between program characteristics, targeted lifestyle factors, and program duration. In addition, detailed information on user evaluation methods and results was often lacking. Pooling of 3 studies that evaluated the effect of a Web-based program $[23,53,58]$ showed a small-to-medium beneficial effect of Web-based multidomain lifestyle interventions on brain health outcomes.

Our main finding that Web-based multidomain lifestyle interventions have a beneficial effect on brain health is in line with previous results from face-to-face lifestyle programs, both reporting modest effect sizes [84,85]. This indicates that Web-based programs have the potential to yield health benefits comparable with those of face-to-face interventions, although no head-to-head comparisons have been made.

For 3 programs, effectiveness was evaluated using a controlled design $[23,53,58]$. In this meta-analysis, heterogeneity between the studies was high, with notable differences in outcome measures. We pooled data from a global cognitive score, a subjective cognitive score, and a risk-score questionnaire. The study on Long Lasting Memories [58] included a group of individuals with heterogeneous cognitive status, ranging from healthy to dementia. Exploratory subgroup analyses showed that the effect of the total intervention group might be conservative and an underestimation for healthy individuals. Although our meta-analysis included individuals over the whole cognitive spectrum, it is noteworthy that the overall intervention effect might be larger in a group of solely healthy individuals.

All described programs stimulated both physical and cognitive activities, that is, 2 lifestyle factors that have been extensively investigated in both healthy and cognitively impaired individuals [86-88]. The content of the Web-based lifestyle programs could be extended by including other lifestyle factors such as smoking, mood, and social activity. Although their influence on brain health may be less well understood, literature suggests that they could be part of a lifestyle that is beneficial for brain health and cognitive functioning [6].

With regard to the targeted lifestyle factors in the meta-analysis, 2 to 7 lifestyle factors (including physical and cognitive activity) were included in their programs. The program with the largest effect size (Body Brain Life [23]; SMD=0.81, 95\% CI 0.43-1.18) targeted 4 lifestyle factors, whereas the program with the smallest effect size (Keep your brain fit [53]; SMD=0.20 95\% CI -0.01 to 0.41 ) targeted 7 lifestyle factors. However, the duration of Body Brain Life was longer than Keep your brain fit (12 weeks and 4 weeks, respectively). Long Lasting Memories ([58]; SMD=0.44 95\% CI 0.15-0.73) targeted 2 lifestyle factors, and, with a 10-week duration, it was in between the 2 latter programs. Due to the heterogeneity, no conclusions can be drawn about the specific successful factors of these programs, other than that at least a physical and cognitive activity were included in all programs and, therefore, seem beneficial for brain health. Better and head-to-head evaluations 
are necessary to compare the number of lifestyle factors, intervention duration, and potential synergistic effects.

Overall, the results of this study are promising, as small-to-medium effect sizes may translate to large public health gains when implemented on a large scale $[19,20]$. In particular, in the context of a global health care burden, given that a 1-year delay of onset of $\mathrm{AD}$ may translate to the prevention of 9 million cases worldwide in 2050 , large-scale prevention with a small effect may be very cost effective [89].

Most of the included programs were not currently available for the general public. The majority were only available in a research setting, and 2 programs were not available online at all $[25,30]$. A sustainable implementation proves a key challenge in the eHealth field [90]. We need to create a bridge between the innovation in health care and the users in the general population. Proper education of health care professionals could increase the perceived usefulness and recommendation of eHealth innovations and, thereby, increase overall implementation success. Fitting the intervention to the needs of the user and making the intervention accessible could improve adherence rates and contribute to this sustainability. Therefore, it is recommended to involve users during every step of the developmental process $[90,91]$. Feedback from users helps to elucidate what a user experiences, which elements are appreciated, and/or to impose a boundary to participate. As concepts in the field of user evaluations are still evolving and used interchangeably [68], clear descriptions of methods and results could contribute to the comparability of the findings. In this review, half of the studies included user evaluations. However, the descriptions of user evaluations were often unclear, with an incomplete or lacking description of methods or lack of specification regarding which questions were asked to evaluate usability, usefulness, and user experience. In the studies that included user evaluations, facilitators for the use of the program were mentioned $[29,32,35,48,62,63]$, such as a program being easy to understand, easy to navigate, and containing interesting content. Barriers that were most often mentioned were of a technical nature [36,49,53,54]. This highlights that the technical development of a program is just as important as the development of content. We recommend to develop the innovation step by step, together with both the technical team and the future users [90], to minimize technical barriers and create content that users deem interesting and useful. Technical features, such as a clear navigation or the possibility to receive reminders, are one of the aspects that influence adherence to a Web-based program.

Sustained adherence to Web-based programs is also an important issue in the eHealth field $[92,93]$. The adherence rates of the described studies were moderate to good and might be related to the tailoring of content $[19,20]$. Although most programs reported to be tailored, it was often unclear on what specific information tailoring was based and how the content was personalized based on this information. When comparing adherence rates between Web-based and face-to-face programs, we found comparable or higher adherence in face-to-face programs than in Web-based programs. For example, the face-to-face multidomain FINGER trial in elderly with cardiovascular risk factors for dementia [15] had high adherence rates (7\% dropout at 12 months), whereas, for example, a face-to-face multidomain study in the frail elderly reported a $24 \%$ dropout mainly because of health problems [94]. Behavior change techniques and the role of communication with peers or a health coach might also influence the adherence rate. These aspects were not included in this review on self-administered programs and, because of the limited description of these aspects in the included documents, overall comparison of this matter with face-to-face programs was not possible.

Despite our extensive search, the small number of original research papers retrieved reflects the limited description of the included Web-based lifestyle programs for brain health and their evaluation. Descriptions might be improved by using a more rigorous design and report. To facilitate a standardized reporting, the CONSORT-EHEALTH (Consolidated Standards of Reporting Trials of Electronic and Mobile HEalth Applications and onLine TeleHealth) Group developed a checklist [95] that could be used during the development of eHealth interventions. This list includes recommendations on the design and, moreover, on the elements that should be included in the reporting of studies. Using this list may improve reporting and provide a basis for evaluation of the validity and applicability of eHealth trials, which might help the field to move forward.

\section{Strengths and Limitations}

A limitation of this study is that the meta-analysis was performed on a small subset of studies. This limitation highlights the premature stage of Web-based lifestyle programs for brain health. Specific limitations of the meta-analysis include the heterogeneous study outcomes, differences in duration of the intervention, differences in the targeted lifestyle factors, and the heterogeneity in the sample of 1 study. However, based on the increasing use of eHealth and the need for dementia prevention strategies, more articles describing a Web-based multidomain lifestyle intervention and its evaluation are expected in the near future.

This overview of Web-based lifestyle programs for brain health was based on an elaborative search in 3 scientific databases, including journal papers as well as gray literature (eg, abstracts). The gray search was useful, as not all programs were described in the full research papers. We used a broad scope of search terms for the inclusion of studies, by widely applying inclusion criteria, for example, not specifying target populations. This broad scope contributes to the generalizability of the findings of this study. Screening of abstracts and full texts was performed by 2 independent raters and, if necessary, consensus meeting with a third rater took place, contributing to the reliability of our findings. Although the studies were highly heterogeneous, systematic elements were combined, resulting in a structured overview of programs and their evaluation. The subset included in the meta-analysis was small and heterogeneous, limiting generalization of the results. Nevertheless, the findings justify further exploration of the possibilities to implement Web-based lifestyle program to optimize brain health. 


\section{Conclusions}

In conclusion, we have provided a systematic overview and meta-analysis of studies on Web-based multidomain lifestyle programs to optimize brain health. Our findings suggest that these programs have a beneficial effect on brain health outcome measures. It would benefit the field if the program characteristics, methods, and results of evaluation of the programs were described in a more consistent way. This would facilitate comparison between programs and contribute to the development and implementation of effective and sustainable programs. Having shown their potential to optimize brain health in large groups of individuals, the implementation of Web-based lifestyle programs may well contribute to the prevention of dementia.

\section{Acknowledgments}

This project was supported by a research grant from the EU Joint Programme-Neurodegenerative Disease Research (JPND_PS_FP-689-019; ZonMw grant no. 733051043)—and a research grant from Stichting Equilibrio. Alzheimer Center Amsterdam is supported by Alzheimer Nederland and Stichting VUmc fonds. Research of the Alzheimer Center Amsterdam is part of the neurodegeneration research program of Neuroscience Amsterdam.

\section{Authors' Contributions}

LW, AH, and SS drafted the manuscript. LW and LS performed the literature search. LW and MW performed screening, study selection, and data extraction. AH, WF and SS supervised the process of screening and data extraction. WF and SS helped with interpretation of the results and manuscript evaluation. All authors have read and approved the final manuscript.

\section{Conflicts of Interest}

None declared.

\section{Multimedia Appendix 1}

Search strategy.

[PDF File (Adobe PDF File), 43KB-Multimedia Appendix 1]

\section{Multimedia Appendix 2}

Systematic search flow chart.

[PDF File (Adobe PDF File), 57KB-Multimedia Appendix 2]

\section{References}

1. Diagnostic and Statistical Manual of Mental Disorders: DSM-5. Washington, DC: American Psychiatric Association; 2013.

2. Stevens T, Livingston G, Kitchen G, Manela M, Walker Z, Katona C. Islington study of dementia subtypes in the community. Br J Psychiatry 2002 Mar;180:270-276. [Medline: 11872521]

3. van der Flier WM, Scheltens P. Amsterdam dementia cohort: performing research to optimize care. J Alzheimers Dis 2018;62(3):1091-1111 [FREE Full text] [doi: 10.3233/JAD-170850] [Medline: 29562540]

4. Prince M, Wimo A, Guerchet M, Ali G, Wu Y, Prina M. Alzheimer's Research UK. London: Alzheimer's Disease International (ADI); 2015. World Alzheimer Report 2015 The Global Impact of Dementia URL: https://www.alz.co.uk/research/ WorldAlzheimerReport2015.pdf [accessed 2019-03-08] [WebCite Cache ID 76ilhNU16]

5. Prince M, Ali GC, Guerchet M, Prina AM, Albanese E, Wu Y. Recent global trends in the prevalence and incidence of dementia, and survival with dementia. Alzheimers Res Ther 2016 Dec 30;8(1):23 [FREE Full text] [doi: 10.1186/s13195-016-0188-8] [Medline: 27473681]

6. Livingston G, Sommerlad A, Orgeta V, Costafreda SG, Huntley J, Ames D, et al. Dementia prevention, intervention, and care. Lancet 2017 Dec 16;390(10113):2673-2734. [doi: 10.1016/S0140-6736(17)31363-6] [Medline: 28735855]

7. Norton S, Matthews FE, Barnes DE, Yaffe K, Brayne C. Potential for primary prevention of Alzheimer's disease: an analysis of population-based data. Lancet Neurol 2014 Aug;13(8):788-794. [doi: 10.1016/S1474-4422(14)70136-X] [Medline: $\underline{25030513]}$

8. de Bruijn RF, Bos MJ, Portegies ML, Hofman A, Franco OH, Koudstaal PJ, et al. The potential for prevention of dementia across two decades: the prospective, population-based Rotterdam Study. BMC Med 2015 Jul 21;13:132 [FREE Full text] [doi: 10.1186/s12916-015-0377-5] [Medline: 26195085]

9. Yaffe K. Modifiable risk factors and prevention of dementia: what is the latest evidence? JAMA Intern Med 2018 Dec 01;178(2):281-282. [doi: 10.1001/jamainternmed.2017.7299] [Medline: 29255907]

10. Schneider N, Yvon C. A review of multidomain interventions to support healthy cognitive ageing. J Nutr Health Aging 2013 Mar;17(3):252-257. [doi: 10.1007/s12603-012-0402-8] [Medline: 23459978] 
11. Andrieu S, Coley N, Lovestone S, Aisen PS, Vellas B. Prevention of sporadic Alzheimer's disease: lessons learned from clinical trials and future directions. Lancet Neurol 2015 Sep;14(9):926-944. [doi: 10.1016/S1474-4422(15)00153-2] [Medline: 26213339]

12. Imtiaz B, Tolppanen A, Kivipelto M, Soininen H. Future directions in Alzheimer's disease from risk factors to prevention. Biochem Pharmacol 2014 Apr 15;88(4):661-670. [doi: 10.1016/j.bcp.2014.01.003] [Medline: 24418410]

13. Ballesteros S, Kraft E, Santana S, Tziraki C. Maintaining older brain functionality: a targeted review. Neurosci Biobehav Rev 2015 Aug;55:453-477. [doi: 10.1016/j.neubiorev.2015.06.008] [Medline: 26054789]

14. Smart CM, Karr JE, Areshenkoff CN, Rabin LA, Hudon C, Gates N, the Subjective Cognitive Decline Initiative (SCD-I) Working Group. Non-pharmacologic interventions for older adults with subjective cognitive decline: systematic review, meta-analysis, and preliminary recommendations. Neuropsychol Rev 2017 Sep;27(3):245-257. [doi: 10.1007/s11065-017-9342-8] [Medline: 28271346]

15. Ngandu T, Lehtisalo J, Solomon A, Levälahti E, Ahtiluoto S, Antikainen R, et al. A 2 year multidomain intervention of diet, exercise, cognitive training, and vascular risk monitoring versus control to prevent cognitive decline in at-risk elderly people (FINGER): a randomised controlled trial. Lancet 2015 Jun 06;385(9984):2255-2263. [doi: 10.1016/S0140-6736(15)60461-5] [Medline: 25771249]

16. Shaw T, McGregor D, Brunner M, Keep M, Janssen A, Barnet S. What is eHealth (6)? Development of a conceptual model for eHealth: Qualitative study with key informants. J Med Internet Res 2017 Oct 24;19(10):e324 [FREE Full text] [doi: 10.2196/jmir.8106] [Medline: 29066429]

17. International Telecommunication Union (ITU). Geneva, Switzerland; 2017. ICT Facts and Figures 2017 URL: https://www. itu.int/en/ITU-D/Statistics/Documents/facts/ICTFactsFigures2017.pdf [accessed 2019-03-08] [WebCite Cache ID 76imR8H1o]

18. McNamee P, Murray E, Kelly MP, Bojke L, Chilcott J, Fischer A, et al. Designing and undertaking a health economics study of digital health interventions. Am J Prev Med 2016 Nov;51(5):852-860. [doi: 10.1016/j.amepre.2016.05.007] [Medline: 27745685]

19. Krebs P, Prochaska JO, Rossi JS. A meta-analysis of computer-tailored interventions for health behavior change. Prev Med 2010;51(3-4):214-221 [FREE Full text] [doi: 10.1016/j.ypmed.2010.06.004] [Medline: 20558196]

20. Lustria ML, Noar SM, Cortese J, Van Stee SK, Glueckauf RL, Lee J. A meta-analysis of web-delivered tailored health behavior change interventions. J Health Commun 2013;18(9):1039-1069. [doi: 10.1080/10810730.2013.768727] [Medline: 23750972]

21. Covidence. Melbourne, Australie URL: https://www.covidence.org/home [accessed 2019-03-05] [WebCite Cache ID 76eAU1eZE]

22. Anstey KJ, Bahar-Fuchs A, Herath PM, Rebok GW, Cherbuin N. A 12-week multidomain intervention versus active control to reduce risk of Alzheimer's disease: study protocol for a randomized controlled trial. Trials 2013 Feb 27;14:60 [FREE Full text] [Medline: 23442574]

23. Anstey KJ, Bahar-Fuchs A, Herath P, Kim S, Burns R, Rebok GW, et al. Body brain life: a randomized controlled trial of an online dementia risk reduction intervention in middle-aged adults at risk of Alzheimer's disease. Alzheimers Dement (N Y) 2015 Jun;1(1):72-80 [FREE Full text] [doi: 10.1016/j.trci.2015.04.003] [Medline: 29854927]

24. Aalbers T, Baars MA, Qin L, de Lange A, Kessels RP, Olde Rikkert MG. Using an eHealth intervention to stimulate health behavior for the prevention of cognitive decline in Dutch adults: a study protocol for the brain aging monitor. JMIR Res Protoc 2015 Nov 10;4(4):e130 [FREE Full text] [doi: 10.2196/resprot.4468] [Medline: 26554496]

25. Aalbers T, Baars L, De Lange A, Kessels R, Olde Rikkert M. Towards a healthier brain with the brain aging monitor. Eur Geriatr Med 2012 Sep;3(Suppl. 1):S133. [doi: 10.1016/j.eurger.2012.07.333]

26. Aalbers T, Qin L, Baars MA, de Lange A, Kessels RP, Olde Rikkert M. Changing behavioral lifestyle risk factors related to cognitive decline in later life using a self-motivated eHealth intervention in Dutch adults. J Med Internet Res 2016 Dec 17;18(6):e171 [FREE Full text] [doi: 10.2196/jmir.5269] [Medline: 27317506]

27. Lawless M, Augoustinos M, LeCouteur A. "Your Brain Matters": issues of risk and responsibility in online dementia prevention information. Qual Health Res 2018 Dec;28(10):1539-1551. [doi: 10.1177/1049732317732962] [Medline: 28974154]

28. Farrow M, O'Connor E, Hatherly C. A randomised controlled trial of e-health interventions for dementia risk reduction. Alzheimers Dement 2014 Jul;10(4):P210. [doi: 10.1016/j.jalz.2014.04.276]

29. O'Connor E, Farrow M, Hatherly C. Randomized comparison of mobile and web-tools to provide dementia risk reduction education: use, engagement and participant satisfaction. JMIR Ment Health 2014;1(1):e4 [FREE Full text] [doi: 10.2196/mental.3654] [Medline: 26543904]

30. Riva CG. DOREMI: smart devices and applications for healthy aging. Cyberpsychol Behav Soc Netw 2017 Apr;20(4):275-276. [doi: 10.1089/cyber.2017.29070.ceu]

31. Wortley D, An JY, Heshmati A. Tackling the challenge of the aging society: detecting and preventing cognitive and physical decline through games and consumer technologies. Healthc Inform Res 2017 Apr;23(2):87-93 [FREE Full text] [doi: 10.4258/hir.2017.23.2.87] [Medline: 28523206] 
32. Clark C, Dorsch T, Gast J, Robinson D, Fauth EB, Hartin PJ, et al. Feedback from middle-aged participants in a multi-domain lifestyle intervention for Alzheimer's prevention: the gray matters study. Alzheimer's \& Dementia 2015 Jul;11(7):P246-P247 [FREE Full text] [doi: 10.1016/j.jalz.2015.07.304]

33. Norton MC, Clark C, Tschanz J, Wengreen H, Fauth EB, Hartin PJ, et al. Improvements over six months in stress management, diet quality, and moderate physical activity are associated with changes in biomarkers of vascular health and inflammation: the gray matters study. Alzheimers Dement 2015 Jul;11(7):P246. [doi: 10.1016/j.jalz.2015.07.303]

34. Clark C. Utah State University. Logan, UT; 2017. Perceived Alzheimer's disease threat as a predictor of behavior change to lower disease risk URL: https://digitalcommons.usu.edu/cgi/viewcontent.cgi?article=5728\&context=etd [accessed 2018-09-07] [WebCite Cache ID 72FfT15k8]

35. Norton MC, Clark CJ, Tschanz JT, Hartin P, Fauth EB, Gast JA, et al. The design and progress of a multidomain lifestyle intervention to improve brain health in middle-aged persons to reduce later Alzheimer's disease risk: The Gray Matters randomized trial. Alzheimers Dement (N Y) 2015 Jun;1(1):53-62 [FREE Full text] [doi: 10.1016/j.trci.2015.05.001] [Medline: 29854925]

36. Richard E, Jongstra S, Soininen H, Brayne C, Moll van Charante EP, Meiller Y, et al. Healthy ageing through internet counselling in the elderly: the HATICE randomised controlled trial for the prevention of cardiovascular disease and cognitive impairment. BMJ Open 2016 Dec 10;6(6):e010806 [FREE Full text] [doi: 10.1136/bmjopen-2015-010806] [Medline: 27288376]

37. Barbera M, Ngandu T, Mangialasche F, Richard E, Beishuizen C, Andrieu S, et al. Management of vascular and lifestyle-related risk factors for alzheimer's disease and dementia in older adults: a European perspective. Alzheimers Dement 2014 Jul;10(4):P754-P755. [doi: 10.1016/j.jalz.2014.05.1434]

38. Mangialasche F, Kivipelto M, Andrieu S, Coley N, Ngandu T, Moll van Charante E, et al. Use of new technology to improve dementia prevention: the Healthy Aging Through Internet Counseling in the Elderly (HATICE) project. Alzheimers Dement 2013 Jul;9(4):P881. [doi: 10.1016/j.jalz.2013.08.231]

39. Kivipelto M, Ngandu T, Solomon A, Rauramaa R, Laatikainen T, Strandberg T, et al. Multi-domain intervention studies to prevent dementia and AD. Neurobiol Aging 2014 Mar;35:S12. [doi: 10.1016/j.neurobiolaging.2014.01.075]

40. Richard E, Mangialsche F, Andrieu S, Barbera M, Beishuizen C, Brayne C, et al. Healthy Ageing Through Internet Counselling in the Elderly (hatice): an ongoing randomised controlled trial. Alzheimer's \& Dementia 2016 Jul;12(7):P1187-P1188. [doi: 10.1016/j.jalz.2016.07.137]

41. Andrieu SN, Kivipelto M, Mangialasche F, Ngandu T, Meiller Y, Guillemont J, et al. Sharing data from ongoing trials to better design new ad prevention trials: The healthy aging through internet counseling in the elderly (HATICE) project. In: Journal of Nutrition, Health and Aging. 2013 Presented at: 6th Conference Clinical Trials on Alzheimer's Disease; 2013; San Diego, CA - USA URL: https://link.springer.com/article/10.1007\%2Fs12603-013-0399-7

42. Coley N, Guillemont J, van Middelaar T, Barbera M, Rosenberg A, Soininen H, MIND-AD and HATICE study groups. Accept-Hatice: a mixed methods study of facilitators and barriers to participation in an internet-based multidomain trial for the prevention of cardiovascular disease and cognitive decline in older European adults. Alzheimers Dement 2017;13(7):P1201-P1202. [doi: 10.1016/j.jalz.2017.06.1798]

43. Coley N, Guillemont J, Rosenberg A, van Middelaar T, Barbera M, Soininen H, et al. Participation in and adherence to an internet-based multidomain trial for the prevention of cardiovascular disease and cognitive decline in French, Finnish and Dutch older adults: data from the ACCEPT-HATICE ancillary study. In: European Geriatric Medicine 2017. 2017 Presented at: 13th International Congress of the European Union Geriatric Medicine Society; 2017 September 20-22; Nice, France p. 20-22 URL: https://eugms2017-abstracts.elsevierdigitaledition.com/files/assets/common/downloads/publication.pdf [doi: 10.1016/S1878-7649(17)30179-1]

44. Coley N, Guillemont J, Martin F, Andrieu S. The HATICE trial in France: focus on the recruitment from a prevention centre. In: European Geriatric Medicine. 2017 Presented at: 13th International Congress of the European Union Geriatric Medicine Society; 2017 September 20-22; Nice, France p. 20-22 URL: https://eugms2017-abstracts.elsevierdigitaledition.com/ files/assets/common/downloads/publication.pdf [doi: 10.1016/S1878-7649(17)30179-1]

45. Jongstra S, Kivipelto M, Soininen HEA. Healthy ageing Through Internet Counselling in the Elderly (HATICE) - Preliminary results from a randomised controlled trial for the prevention of cardiovascular disease and cognitive impairment. In: European Stroke Journal. 2016 Presented at: 2nd European Stroke Organisation Conference; 2016 May 10-12; Barcelona, Spain p. 10-12.

46. Richard E. Healthy ageing through internet counselling in the elderly. In: Alzheimers Dement. 2017 Presented at: AAIC 2017; July 2017; London URL: https://doi.org/10.1016/j.jalz.2017.07.393 [doi: 10.1016/j.jalz.2017.07.393]

47. Coley N, Andrieu S, Mangialasche F. Healthy Ageing Through Internet Counselling in the Elderly (HATICE) - an ongoing randomised controlled trial. In: European Geriatric Medicine. 2017 Presented at: 13th International Congress of the European Union Geriatric Medicine Society; September 20-22, 2017; Nice, France.

48. van Middelaar T, Beishuizen CR, Guillemont J, Barbera M, Richard E, Moll van Charante EP, HATICE consortium. Engaging older people in an internet platform for cardiovascular risk self-management: a qualitative study among Dutch HATICE participants. BMJ Open 2018 Dec 21;8(1):e019683 [FREE Full text] [doi: 10.1136/bmjopen-2017-019683] [Medline: 29358447] 
49. Jongstra S, Beishuizen C, Andrieu S, Barbera M, van Dorp M, van der Groep B, et al. Development and validation of an interactive internet platform for older people: the healthy ageing through internet counselling in the elderly study. Telemed J E Health 2017 Dec;23(2):96-104. [doi: 10.1089/tmj.2016.0066] [Medline: 27463120]

50. O'Donnell CA, Browne S, Pierce M, McConnachie A, Deckers K, van Boxtel MP, In-MINDD Team. Reducing dementia risk by targeting modifiable risk factors in mid-life: study protocol for the Innovative Midlife Intervention for Dementia Deterrence (In-MINDD) randomised controlled feasibility trial. Pilot Feasibility Stud 2015 Nov; 1:40 [FREE Full text] [doi: 10.1186/s40814-015-0035-x] [Medline: 27965818]

51. Pierce M, Redmond M, Irving K. Towards a profile of dementia risk and online supports for dementia risk reduction: translating findings from a robust model based on modifiable risk factors. In: Irish Journal of Medical Science. 2014 Presented at: 62nd Annual and Scientific Meeting of the Irish Gerontological Society; October 9-11; Galway, Ireland p. 9-11.

52. Schiepers OJ, Köhler S, Deckers K, Irving K, O'Donnell CA, van den Akker M, et al. Lifestyle for Brain Health (LIBRA): a new model for dementia prevention. Int J Geriatr Psychiatry 2018 Jan;33(1):167-175. [doi: 10.1002/gps.4700] [Medline: $\underline{28247500]}$

53. Reijnders JS, Geusgens CA, Ponds RW, van Boxtel MP. "Keep your brain fit!" Effectiveness of a psychoeducational intervention on cognitive functioning in healthy adults: a randomised controlled trial. Neuropsychol Rehabil 2017 Jun;27(4):455-471. [doi: 10.1080/09602011.2015.1090458] [Medline: 26414279]

54. Lara J, O'Brien N, Godfrey A, Heaven B, Evans EH, Lloyd S, et al. Pilot randomised controlled trial of a web-based intervention to promote healthy eating, physical activity and meaningful social connections compared with usual care control in people of retirement age recruited from workplaces. PLoS One 2016;11(7):e0159703 [FREE Full text] [doi: 10.1371/journal.pone.0159703] [Medline: 27472560]

55. Bamidis PD, Konstantinidis EI, Billis A, Frantzidis C, Tsolaki M, Hlauschek W, et al. A web services-based exergaming platform for senior citizens: the Long Lasting Memories project approach to e-health care. Conf Proc IEEE Eng Med Biol Soc 2011:167-175. [doi: 10.1109/IEMBS.2011.6090694] [Medline: 22254850]

56. Konstantinidis EI, Bamparopoulos G, Bamidis PD. Moving real exergaming engines on the web: the webFitForAll case study in an active and healthy ageing living lab environment. IEEE J Biomed Health Inform 2017 Dec;21(3):859-866. [doi: 10.1109/JBHI.2016.2559787] [Medline: 28113566]

57. Konstantinidis EI, Billis A, Hlauschek W, Panek P, Bamidis PD. Integration of cognitive and physical training in a smart home environment for the elderly people. Stud Health Technol Inform 2010;160(Pt 1):58-62. [Medline: 20841650]

58. Bamidis PD, Fissler P, Papageorgiou SG, Zilidou V, Konstantinidis EI, Billis AS, et al. Gains in cognition through combined cognitive and physical training: the role of training dosage and severity of neurocognitive disorder. Front Aging Neurosci 2015;7:152 [FREE Full text] [doi: 10.3389/fnagi.2015.00152] [Medline: 26300772]

59. González-Palau F, Franco M, Bamidis P, Losada R, Parra E, Papageorgiou SG, et al. The effects of a computer-based cognitive and physical training program in a healthy and mildly cognitive impaired aging sample. Aging Ment Health 2014 Sep;18(7):838-846. [doi: 10.1080/13607863.2014.899972] [Medline: 24697325]

60. Brodaty H, Heffernan M, Fiatarone Singh MA, Valenzuela M, Andrews G, Lautenschlager NT, et al. Maintain Your Brain: a randomised controlled trial of an internet-based multi-component lifestyle intervention to prevent cognitive decline and dementia. Alzheimer's \& Dementia 2017 Jul;13(7):P1216. [doi: 10.1016/j.jalz.2017.07.390]

61. Brodaty H. Maximising technology and methodology for internet prevention of cognitive decline: the maintain your brain trial. In: Alzheimers Dement. 2017 Presented at: AAIC 2017; July 2017; London. [doi: 10.1016/j.jalz.2017.07.409]

62. Babiloni C, Guarini A, Lizio R, Cordone S, Bonaduce R, Armenise V, et al. Prevention of mental disorders in seniors at risk of alzheimer's disease in the smart health project: the smartaging platform. Alzheimers Dement 2016 Jul;12(7):P592-P593. [doi: 10.1016/j.jalz.2016.06.1165]

63. Caprara M, Molina MA, Schettini R, Santacreu M, Orosa T, Mendoza-Núñez VM, et al. Active aging promotion: results from the vital aging program. Curr Gerontol Geriatr Res 2013;2013:817813 [FREE Full text] [doi: 10.1155/2013/817813] [Medline: 23476644]

64. Caprara M, Fernández-Ballesteros R, Alessandri G. Promoting aging well: evaluation of Vital-Aging-Multimedia Program in Madrid, Spain. Health Promot Int 2016 Sep;31(3):515-522. [doi: 10.1093/heapro/dav014] [Medline: 25784303]

65. Maher CG, Sherrington C, Herbert RD, Moseley AM, Elkins M. Reliability of the PEDro scale for rating quality of randomized controlled trials. Phys Ther 2003 Aug;83(8):713-721. [Medline: 12882612]

66. Yamato TP, Maher C, Koes B, Moseley A. The PEDro scale had acceptably high convergent validity, construct validity, and interrater reliability in evaluating methodological quality of pharmaceutical trials. J Clin Epidemiol 2017 Jun;86:176-181. [doi: 10.1016/j.jclinepi.2017.03.002] [Medline: 28288916]

67. Verhagen AP, de Vet HC, de Bie RA, Kessels AG, Boers M, Bouter LM, et al. The Delphi list: a criteria list for quality assessment of randomized clinical trials for conducting systematic reviews developed by Delphi consensus. J Clin Epidemiol 1998 Dec;51(12):1235-1241. [Medline: 10086815 ]

68. Rusu C, Rusu V, Roncagliolo S, González C. Usability and User Experience. Int J Inf Technol Syst Approach 2015;8(2):1-12. [doi: 10.4018/IJITSA.2015070101] 
69. Sieverink F, Kelders SM, van Gemert-Pijnen JE. Clarifying the concept of adherence to eHealth technology: systematic review on when usage becomes adherence. J Med Internet Res 2017 Dec 06;19(12):e402 [FREE Full text] [doi: 10.2196/jmir.8578] [Medline: 29212630]

70. IBM Corp. Armonk, New York; 2013. IBM SPSS software URL: https://www.ibm.com/analytics/spss-statistics-software [accessed 2019-03-05] [WebCite Cache ID 76eBNihYG]

71. Higgins JP, Thompson SG. Quantifying heterogeneity in a meta-analysis. Stat Med 2002 Jun 15;21(11):1539-1558. [doi: 10.1002/sim.1186] [Medline: 12111919]

72. Higgins JP, Thompson SG, Deeks JJ, Altman DG. Measuring inconsistency in meta-analyses. Br Med J 2003 Sep 6;327(7414):557-560 [FREE Full text] [doi: 10.1136/bmj.327.7414.557] [Medline: $\underline{12958120}$ ]

73. Anstey KJ, Cherbuin N, Herath PM. Development of a new method for assessing global risk of Alzheimer's disease for use in population health approaches to prevention. Prev Sci 2013 Aug;14(4):411-421 [FREE Full text] [doi:

10.1007/s11121-012-0313-2] [Medline: 23319292]

74. Aalbers T, Baars MA, Olde RM, Kessels RP. Puzzling with online games (BAM-COG): reliability, validity, and feasibility of an online self-monitor for cognitive performance in aging adults. J Med Internet Res 2013;15(12):e270 [FREE Full text] [doi: 10.2196/jmir.2860] [Medline: 24300212]

75. Nasreddine Z, Phillips N, Bédirian V, Charbonneau S, Whitehead V, Collin I, et al. The Montreal Cognitive Assessment, MoCA: a brief screening tool for mild cognitive impairment. J Am Geriatr Soc 2005 Apr;53(4):695-699. [doi: 10.1111/j.1532-5415.2005.53221.x] [Medline: 15817019 ]

76. De Renzi E, Vignolo L. The token test: a sensitive test to detect receptive disturbances in aphasics. Brain 1962 Apr;85(4):665-678. [doi: 10.1093/brain/85.4.665]

77. Rubenstein LZ, Harker JO, Salvà A, Guigoz Y, Vellas B. Screening for undernutrition in geriatric practice: developing the short-form mini-nutritional assessment (MNA-SF). J Gerontol A Biol Sci Med Sci 2001 Jun;56(6):M366-M372. [Medline: 11382797]

78. Ponds RW, Jolles J. The Abridged Dutch Metamemory in Adulthood (MIA) Questionnaire: structure and effects of age, sex, and education. Psychol Aging 1996 Jun;11(2):324-332. [Medline: 8795061]

79. Broadbent DE, Cooper PF, FitzGerald P, Parkes KR. The Cognitive Failures Questionnaire (CFQ) and its correlates. Br J Clin Psychol 1982 Feb;21 (Pt 1):1-16. [Medline: 7126941]

80. Ponds R, van Boxtel M, Jolles J. De 'Cognitive Failure Questionnaire' als maat voor subjectief functioneren [Dutch]. Tijdschrift voor neuropsychologie 2006;1(2):37-42 [FREE Full text]

81. Hoogenhout EM, de Groot RH, van der Elst W, Jolles J. Effects of a comprehensive educational group intervention in older women with cognitive complaints: a randomized controlled trial. Aging Ment Health 2012;16(2):135-144. [doi: 10.1080/13607863.2011.598846] [Medline: 21780962]

82. Liu B, Young H, Crowe FL, Benson VS, Spencer EA, Key TJ, et al. Development and evaluation of the Oxford WebQ, a low-cost, web-based method for assessment of previous $24 \mathrm{~h}$ dietary intakes in large-scale prospective studies. Public Health Nutr 2011 Nov;14(11):1998-2005. [doi: 10.1017/S1368980011000942] [Medline: 21729481]

83. Folstein MF, Folstein SE, McHugh PR. "Mini-mental state". A practical method for grading the cognitive state of patients for the clinician. J Psychiatr Res 1975 Nov;12(3):189-198. [Medline: 1202204]

84. Lampit A, Hallock H, Valenzuela M. Computerized cognitive training in cognitively healthy older adults: a systematic review and meta-analysis of effect modifiers. PLoS Med 2014 Nov;11(11):e1001756 [FREE Full text] [doi: 10.1371/journal.pmed.1001756] [Medline: 25405755]

85. Smith PJ, Blumenthal JA, Hoffman BM, Cooper H, Strauman TA, Welsh-Bohmer K, et al. Aerobic exercise and neurocognitive performance: a meta-analytic review of randomized controlled trials. Psychosom Med 2010 Apr;72(3):239-252 [FREE Full text] [doi: 10.1097/PSY.0b013e3181d14633] [Medline: 20223924]

86. de Labra C, Guimaraes-Pinheiro C, Maseda A, Lorenzo T, Millán-Calenti JC. Effects of physical exercise interventions in frail older adults: a systematic review of randomized controlled trials. BMC Geriatr 2015;15:154 [FREE Full text] [doi: 10.1186/s12877-015-0155-4] [Medline: 26626157]

87. Groot C, Hooghiemstra AM, Raijmakers PG, van Berckel BN, Scheltens P, Scherder EJ, et al. The effect of physical activity on cognitive function in patients with dementia: a meta-analysis of randomized control trials. Ageing Res Rev 2016 Jan;25:13-23. [doi: 10.1016/j.arr.2015.11.005] [Medline: 26607411]

88. Mewborn CM, Lindbergh CA, Stephen Miller L. Cognitive interventions for cognitively healthy, mildly impaired, and mixed samples of older adults: a systematic review and meta-analysis of randomized-controlled trials. Neuropsychol Rev 2017 Dec;27(4):403-439. [doi: 10.1007/s11065-017-9350-8] [Medline: 28726168]

89. Brookmeyer R, Johnson E, Ziegler-Graham K, Arrighi HM. Forecasting the global burden of Alzheimer's disease. Alzheimers Dement 2007 Jul;3(3):186-191. [doi: 10.1016/j.jalz.2007.04.381] [Medline: 19595937]

90. van Gemert-Pijnen JE, Nijland N, van Limburg M, Ossebaard HC, Kelders SM, Eysenbach G, et al. A holistic framework to improve the uptake and impact of eHealth technologies. J Med Internet Res 2011;13(4):e111 [FREE Full text] [doi: 10.2196/jmir.1672] [Medline: 22155738] 
91. Wesselman LM, Schild A, Coll-Padros N, van der Borg WE, Meurs JHP, Hooghiemstra AM, Euro-SCD working group. Wishes and preferences for an online lifestyle program for brain health-A mixed methods study. Alzheimers Dement (N Y) 2018;4:141-149 [FREE Full text] [doi: 10.1016/j.trci.2018.03.003] [Medline: 29955658]

92. Cugelman B, Thelwall M, Dawes P. Online interventions for social marketing health behavior change campaigns: a meta-analysis of psychological architectures and adherence factors. J Med Internet Res 2011;13(1):e17 [FREE Full text] [doi: 10.2196/jmir.1367] [Medline: 21320854]

93. Schubart JR, Stuckey HL, Ganeshamoorthy A, Sciamanna CN. Chronic health conditions and internet behavioral interventions: a review of factors to enhance user engagement. Comput Inform Nurs 2011 Feb;29(2):81-92. [doi: 10.1097/NCN.0b013e3182065eed] [Medline: 21164337]

94. de Jong N, Chin A Paw MJ, de Groot LC, Rutten RA, Swinkels DW, Kok FJ, et al. Nutrient-dense foods and exercise in frail elderly: effects on B vitamins, homocysteine, methylmalonic acid, and neuropsychological functioning. Am J Clin Nutr 2001 Feb;73(2):338-346. [doi: 10.1093/ajcn/73.2.338] [Medline: 11157333]

95. Eysenbach G, CONSORT-EHEALTH Group. CONSORT-EHEALTH: improving and standardizing evaluation reports of web-based and mobile health interventions. J Med Internet Res 2011 Dec 31;13(4):e126 [FREE Full text] [doi: 10.2196/jmir.1923] [Medline: 22209829]

\author{
Abbreviations \\ AD: Alzheimer disease \\ eHealth: electronic health \\ FINGER: Finnish Geriatric Intervention Study to Prevent Cognitive Impairment and Disability \\ HATICE: Healthy Aging Through Internet Counselling in the Elderly \\ ISO: International Organization of Standardization LEAP: Lifestyle Enrichment for Alzheimer Prevention \\ PEDro scale: physiotherapy evidence database scale \\ PRISMA: Preferred Reporting Items for Systematic Reviews and Meta-Analysis \\ SMD: standardized mean difference
}

Edited by P Bamidis; submitted 07.09.18; peer-reviewed by E Madero, P Simon, F Nuñez-Benjumea, C Tziraki; comments to author
05.12.18; revised version received 28.01.19; accepted 14.02.19; published 09.04.19
Please cite as:
Wesselman LMP, Hooghiemstra AM, Schoonmade LJ, de Wit MCJ, van der Flier WM, Sikkes SAM
Web-Based Multidomain Lifestyle Programs for Brain Health: Comprehensive Overview and Meta-Analysis
JMIR Ment Health 2019;6(4):e12104
URL: $\underline{\text { http://mental.jmir.org/2019/4/e12104/ }}$
doi: $\underline{10.2196 / 12104}$
PMID: $\underline{30964438}$

CLinda MP Wesselman, Astrid M Hooghiemstra, Linda J Schoonmade, Marjolein CJ de Wit, Wiesje M van der Flier, Sietske AM Sikkes. Originally published in JMIR Mental Health (http://mental.jmir.org), 09.04.2019. This is an open-access article distributed under the terms of the Creative Commons Attribution License (https://creativecommons.org/licenses/by/4.0/), which permits unrestricted use, distribution, and reproduction in any medium, provided the original work, first published in JMIR Mental Health, is properly cited. The complete bibliographic information, a link to the original publication on http://mental.jmir.org/, as well as this copyright and license information must be included. 